\title{
Influence of food matrix type on extracellular products of Vibrio parahaemolyticus
}

\author{
Rundong Wang ${ }^{1}$, Lijun Sun ${ }^{1 *}$ (D, Yaling Wang ${ }^{1 *}$, Yijia Deng ${ }^{1}$, Zhijia Fang ${ }^{1}$, Ying Liu', Qi Deng ${ }^{1}$, Dongfang Sun ${ }^{1}$ \\ and Ravi Gooneratne ${ }^{2}$
}

\begin{abstract}
Background: Two strains of Vibrio parahaemolyticus (ATCC 17802 and 33847) in shrimp, oyster, freshwater fish, pork, chicken and egg fried rice were evaluated for production of hemolysin and exoenzymes of potential importance to the pathogenicity of this bacterium.

Results: The two strains of $V$. parahaemolyticus produced hemolysin, gelatinase, caseinase, phospholipase, urease, DNase and amylase in selected food matrices. Significantly higher $(p<0.05)$ hemolytic activity was produced by $V$. parahaemolyticus in egg fried rice $>$ shrimp $>$ freshwater fish $>$ chicken $>$ oyster $>$ pork. But the exoenzyme activities were not consistent with the hemolytic activity profile, being significantly higher $(p<0.05)$ in shrimp > freshwater fish $>$ chicken $>$ oyster $>$ pork $>$ egg fried rice. Filtrates of $V$. parahaemolyticus from shrimp, freshwater fish and chicken given intraperitoneally to adult mice induced marked liver and kidney damage and were highly lethal compared with the filtrates of $V$. parahaemolyticus from oyster $>$ egg fried rice $>$ pork.

Conclusion: From in vitro and in vivo tests, it appears that the food matrix type has a significant impact on the activity of extracellular products and the pathogenicity of $V$. parahaemolyticus. From a food safety aspect, it is important to determine which food matrices can stimulate $V$. parahaemolyticus to produce additional extracellular factors. This is the first report of non-seafood including freshwater fish and chicken contaminated with $V$. parahaemolyticus to have been shown to be toxic to mice in vivo.
\end{abstract}

Keywords: Vibrio parahaemolyticus, Food matrices, Extracellular products, Pathogenicity

\section{Background}

Vibrio parahaemolyticus is a gram-negative, facultative, anaerobic, halophilic bacterium that inhabits marine or estuarine environments $[1,2]$. The natural host for this bacterium is variable because it lives in water and is concentrated in shellfish which can serve as reservoirs [3-5]. V. parahaemolyticus can contaminate raw or undercooked shrimp, fish, oyster and cause abdominal pain, acute gastroenteritis, diarrhea, and infection by the O3: $\mathrm{K} 6$ pandemic strain resulted in a massive number of

\footnotetext{
* Correspondence: suncamt@126.com; wangylchina@163.com

${ }^{1}$ College of Food Science and Technology, Guangdong Provincial Key Laboratory of Aquatic Product Processing and Safety, Key Laboratory of Advanced Processing of Aquatic Products of Guangdong Higher Education Institution, Guangdong Ocean University, Zhanjiang 524088, China
} Full list of author information is available at the end of the article human deaths [6-8] in several countries including China, Japan and the United States [9-11].

Following contamination of food with $V$. parahaemolyticus, both the bacterial cells and extracellular products contribute to the pathogenicity and among them, the extracellular products play a dominant role [12-14]. Of all extracellular products, hemolysin (thermostable direct hemolysin, thermostable-related hemolysin) is regarded as the most important virulence factor, and controls a variety of biological activities including hemolytic activity, cytotoxicity, and enterotoxicity [15-17], besides other factors such as exoenzymes $[18,19]$. Among these, gelatinase and caseinase belong to a family of proteolytic enzymes that can cause tissue damage and hydrolyze various protein substrates including hemoglobin and other small amounts of biologically

(c) The Author(s). 2018 Open Access This article is distributed under the terms of the Creative Commons Attribution 4.0 International License (http://creativecommons.org/licenses/by/4.0/), which permits unrestricted use, distribution, and 
active peptides [20, 21]. Phospholipases involved in nutrient acquisition through the degradation of membrane lipids may also cause harm to the host [22]. DNase can act as endonuclease and contribute to DNA hydrolysis, amylase can hydrolyze carbohydrate to provide energy for the growth of $V$. parahaemolyticus [23] and urease may act as hemolysin [24].

Seafood has long been considered to be the only carrier of $V$. parahaemolyticus. Therefore, from a food safety aspect, more attention has been paid to seafood products. However, there is new evidence that $V$. parahaemolyticus can also contaminate non-seafood matrices (a prevalence of $\sim 32.5 \%$ ) such as poultry, pork, freshwater fish, eggs and their products including egg fried rice, by cross contamination of seafood to non-seafood and via cooking utensils [25-27], which suggest that $V$. parahaemolyticus can also cause food infection via many non-seafood types. Our previous studies [28] found that the virulence factors of $V$. parahaemolyticus can trigger high or low pathogenicity in different foods. But, little is known of the composition of extracellular products in different food matrices.

To better assess the risk of $V$. parahaemolyticus in different food matrices, a clearunderstanding of the extracellular products is essential. In this study, we examined the importance of extracellular products, hemolysins, gelatinase, caseinase, phospholipase, urease, DNase and amylase to the pathogenicity of $V$. parahaemolyticus in selected seafood and non-seafood products and tested their combined pathogenicity in a mouse model.

\section{Methods}

\section{Bacterial strains and growth conditions}

V. parahaemolyticus strains ATCC 17802 and ATCC 33847 were stored in $25 \%$ glycerol at $-20{ }^{\circ} \mathrm{C}$. Each strain was grown in brain heart infusion (BHI) broth (BLBT, Beijing, China) containing $3 \% \mathrm{NaCl}$, at $37{ }^{\circ} \mathrm{C}$ for $24 \mathrm{~h}$. The inoculum was thrice passaged in $\mathrm{BHI}-3 \% \mathrm{NaCl}$. The final concentration of inoculants were adjusted to $10^{4} \mathrm{CFU} / \mathrm{ml}$ and used to inoculate the food matrices.

\section{Food matrices preparation and inoculation}

Shrimp (Litopenaeus vannamei), oyster (Crassostrea), freshwater fish (Tilapia), pork and chicken were purchased from a local supermarket in Zhanjiang, China, and the meat was used in the study. Egg fried rice (rice:egg $=1: 1$ ) was cooked at $80{ }^{\circ} \mathrm{C}$ for $20 \mathrm{~min}$, in the laboratory.

Test portions, $100 \mathrm{~g}$ each $(n=3)$ of shrimp meat, oyster, freshwater fish meat, pork, chicken, and egg fried rice, added salt at $3 \%$ in sterile Erlenmeyer flasks were sterilized by autoclave (YXQ-L-50A, Shanghai Boxun, Shanghai, China) at $100{ }^{\circ} \mathrm{C}$ for $20 \mathrm{~min}$ to kill native bacteria. Then each sample was inoculated with either $1 \mathrm{~mL}$ of the final $V$. parahaemolyticus ATCC 17802 or ATCC 33847 (described above, cell number $\sim 10^{3} \mathrm{CFU} / \mathrm{g}$ ). Inoculated samples were mixed thoroughly in a vortex mixer (XW-80A, Qilinbei, Haimen, China) for $10 \mathrm{~min}$ and incubated at $37{ }^{\circ} \mathrm{C}$ until the bacterial counts were approximately $10^{9} \mathrm{CFU} / \mathrm{g}$.

After incubation, the inoculated food samples were separately washed with $100 \quad \mathrm{~mL} \quad 0.01 \quad \mathrm{M}$ phosphate-buffered saline (PBS, $\mathrm{pH}$ 7.2), and the solution centrifuged (Thermo Lynx 6000, Thermo Scientific, Waltham, MA) at $12000 \mathrm{rpm}$ for $20 \mathrm{~min}$ at $4{ }^{\circ} \mathrm{C}$. The supernatants were filtered $(0.22 \mu \mathrm{m}$, Millipore, Billerica, MA) and stored at $-20{ }^{\circ} \mathrm{C}$ until use. The control food matrix samples were subjected to the same procedure except that these samples were not inoculated with $V$. parahaemolyticus.

\section{Hemolytic activity}

The relative hemolytic activity test measured the total hemolysins in the samples and were detected as described by Takamatsu et al. [29] modified by Jiang et al. [30]. Rabbit hemocytes were obtained by centrifugation of blood ( $3500 \mathrm{rpm}, 4{ }^{\circ} \mathrm{C}, 5 \mathrm{~min}$ ) three times (washed with PBS each time) and diluted to $5 \%$ with PBS. Subsequently, a sample $(400 \mu \mathrm{L})$ of each food matrix was mixed with $100 \mu \mathrm{L}$ of $5 \%$ rabbit red blood cells in 1.5 -mL sterile tubes and incubated at $37{ }^{\circ} \mathrm{C}$ for $1.5 \mathrm{~h}$. Unlysed erythrocytes were allowed to pelletize overnight at $4{ }^{\circ} \mathrm{C}$, then $200-\mu \mathrm{L}$ portions of the supernatant were transferred to 96-well flat-bottomed microplates (Nunc, Thermo Scientific, Waltham, MA) and the absorbance measured at $570 \mathrm{~nm}$ with a microplate reader (Varioskan Flash, Thermo Scientific, Waltham, MA). For controls, the same procedure was employed except the samples were changed to food matrix filtrates without the $V$. parahaemolyticus inocula. The results are reported as: $\mathrm{A}_{\text {relative hemolytic activity }}=\mathrm{A}_{\text {sample }}-\mathrm{A}_{\text {control }}$.

\section{Production of extracellular enzymes}

In separate plates, $0.5 \%(w / v)$ gelatin [31], $0.2 \%(w / v)$ casein [32], 3\% (v/v) egg yolk emulsion, $2.5 \%(\mathrm{w} / \mathrm{v})$ urea [31], $0.01 \%(\mathrm{w} / \mathrm{v})$ toluidine blue or $0.2 \%(\mathrm{w} / \mathrm{v})$ soluble starch [14] were added to tryptone soya agar (TSA) to determine gelatinase, caseinase, phospholipase, urease, DNase and amylase enzyme activities.

The exoenzyme activities of sample and control filtrates were determined by the Oxford Cup Method [33]. Briefly, $180 \mu \mathrm{L}$ of the filtrate in triplicate were added into the Oxford cups in TSA plates containing different substrates. All the plates were incubated at $37{ }^{\circ} \mathrm{C}$ for $12 \mathrm{~h}$. The positive reaction of a clear halo was detected with gelatinase and caseinase following addition of 70\% trichloroacetic acid. The positive reaction to phospholipase, urease, and DNase were characterized by the 
presence of opaque halo, yellow halo, and pink halo respectively. To detect amylase, $5 \mathrm{mmol} / \mathrm{L} \mathrm{KI}-\mathrm{I}_{2}$ solution was added to the TSA plates after the 12-h incubation and a clear halo indicated a positive reaction. All positive zones around the cup were measured.

\section{Mice pathogenicity test Lethality study}

One hundred and eight female KM mice $(20 \pm 2$ g, 6 weeks old) were obtained from Animal Center of Guang Dong Province. During the experimental period, mice were reared under standard laboratory conditions (12 h light-dark cycle, temperature of $20 \pm 1{ }^{\circ} \mathrm{C}$, humidity $60 \pm 5 \%)$ in 18 stainless steel cages with free access to distilled water and sterilized food. The mice were acclimatized to this environment for 5 days randomly assigned to 18 groups $(n=6)$. Twelve experimental groups were injected with millipore-filtered food matrix filtrates contaminated with either $V$. parahaemolyticus ATCC 17802 or ATCC 33847 strain, and six control groups with control food matrix filtrates, intraperitoneally (i.p.) at $0.2 \mathrm{~mL} / 10 \mathrm{~g}$ body weight (bw). The mortality rate of mice was recorded for $48 \mathrm{~h}$.

\section{Biochemical indices}

For biochemical studies, another 108, 6-week-old female KM mice (obtained from Animal Center of Guang Dong Province) were injected i.p. with $V$. parahaemolyticus food matrix filtrates as per the above described protocol. Mice were euthanized by exsanguination while under ether vapor narcosis (in a funnel) at $12 \mathrm{~h}$. Blood was sampled by percutaneous cardiac puncture and centrifuged at $3500 \mathrm{rpm}$ for $10 \mathrm{~min}$ to obtain serum for detection of three liver-specific enzymes (aspartate aminotransferase (AST), alanine aminotransferase (ALT) and alkaline phosphatase (ALP)) and the kidney-specific enzyme blood urea nitrogen (BUN), using detection kits (Nanjing Jiancheng Bioengineering Institute, Nanjing, China), to assess tissue damage.

\section{Ethics approval and consent to participate}

All mouse experiments were conducted according to the guidelines provided by the.

Animal Care and Welfare Committee of Guangdong Ocean University (License Number: SYXK 2014-0053).

\section{Statistical analysis}

All data were analyzed using the software SPSS 19.0 (SPSS Inc., Chicago, IL, USA). Differences between the means were tested by one-way ANOVA, with the level of significance set at $p<0.05$.

\section{Results}

\section{Hemolytic activity}

The relative absorbance of different food matrices filtrates reflected the hemolytic activity of $V$. parahaemolyticus in food samples. The $V$. parahaemolyticus ATCC 33847 showed a higher hemolytic activity than ATCC 17802 in all selected food samples. Irrespective of the $V$. parahaemolyticus strain, the hemolytic activity was significantly higher in egg fried rice $>$ shrimp $>$ freshwater fish $>$ chicken $>$ oyster $>$ pork (Fig. 1).

\section{Production of extracellular enzymes}

ATCC 17802 and ATCC 33847 strains were tested for six exoenzymes previously reported to be responsible for $V$. parahaemolyticus virulence. The two pathogenic strains of $V$. parahaemolyticus produced a wide variety of extracellular enzymes including gelatinase, caseinase, phospholipase, urease, DNase and amylase in the selected food matrices (Table 1). Extracellular factor activity was generally higher with the ATCC 33847 strain than with ATCC 17802. Overall, both $V$. parahaemolyticus strains produced significantly high activities $(p<$ 0.05 ) of gelatinase, caseinase, phospholipase, urease, DNase and amylase in shrimp > freshwater fish > chicken $>$ oyster $>$ pork $>$ egg fried rice.

\section{Mice pathogenicity tests Lethality}

The mortality of mice injected with the food matrix filtrates was higher with the shrimp matrix than other food matrices (Table 2) probably because of the higher extracellular enzyme activity). The mortality rate was highest in shrimp $>$ freshwater fish $>$ chicken $>$ oyster $>$ egg fried rice $>$ pork. Strain ATCC 33847 appeared more

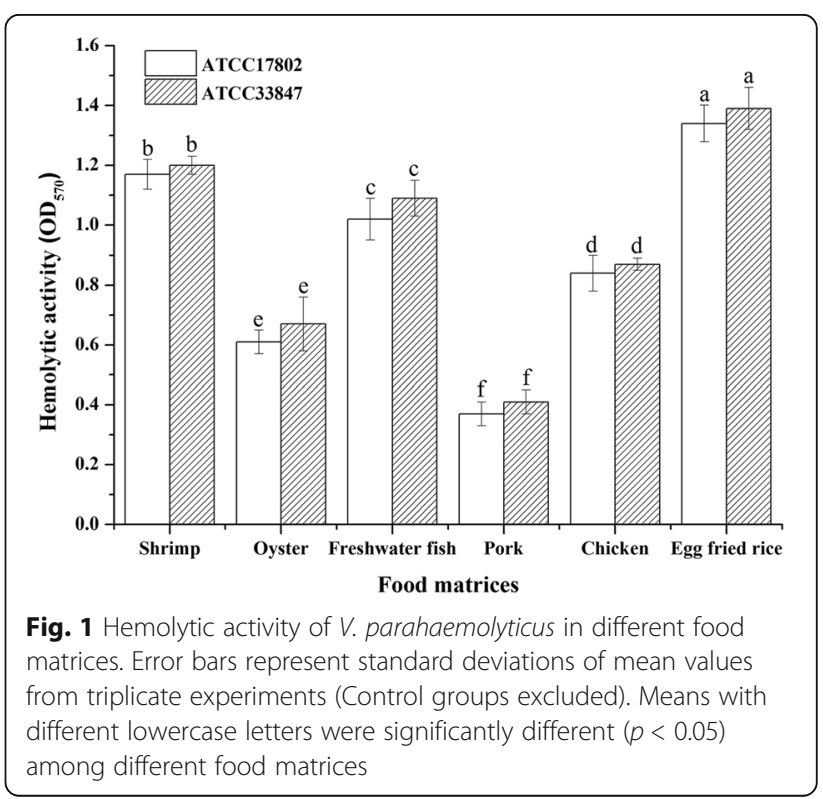


Table 1 Extracellular enzyme composition and activity of Vibrio parahaemolyticus in different food matrices ${ }^{f}$

\begin{tabular}{|c|c|c|c|c|c|c|c|c|}
\hline \multirow{2}{*}{$\begin{array}{l}\text { Measurement } \\
\text { index }\end{array}$} & \multirow[t]{2}{*}{ Enzyme } & \multirow[t]{2}{*}{ Strains } & \multicolumn{6}{|l|}{ Food matrix } \\
\hline & & & Shrimp & Oyster & Freshwater fish & Pork & Chicken & Egg fried rice \\
\hline \multirow{12}{*}{$\begin{array}{l}\text { Positive circle } \\
\text { diameter (mm) }\end{array}$} & \multirow[t]{2}{*}{ Gelatinase } & ATCC 17802 & $21.98 \pm 2.10^{\mathrm{a}}$ & $15.92 \pm 1.39^{d}$ & $20.72 \pm 1.98^{b}$ & $15.00 \pm 1.67^{e}$ & $17.52 \pm 1.44^{c}$ & $16.56 \pm 1.12^{c}$ \\
\hline & & ATCC 33847 & $29.42 \pm 1.71^{\mathrm{a}}$ & $17.20 \pm 1.39^{c}$ & $21.12 \pm 1.45^{b}$ & $14.88 \pm 1.56^{\mathrm{e}}$ & $18.29 \pm 0.99^{c}$ & $16.16 \pm 0.91^{d}$ \\
\hline & \multirow[t]{2}{*}{ Caseinase } & ATCC 17802 & $25.62 \pm 2.25^{a}$ & $18.16 \pm 1.41^{c}$ & $20.32 \pm 1.32^{b}$ & $17.10 \pm 1.08^{d}$ & $24.40 \pm 3.06^{a}$ & $13.94 \pm 2.64^{e}$ \\
\hline & & ATCC 33847 & $26.20 \pm 1.19^{a}$ & $18.08 \pm 0.99^{c}$ & $22.80 \pm 0.92^{b}$ & $12.60 \pm 1.52^{\mathrm{e}}$ & $19.40 \pm 1.38^{c}$ & $14.40 \pm 2.58^{d}$ \\
\hline & \multirow[t]{2}{*}{ Phospholipase } & ATCC 17802 & $14.90 \pm 1.24^{b}$ & $9.20 \pm 1.31^{\mathrm{e}}$ & $12.50 \pm 0.79^{c}$ & $14.04 \pm 1.10^{b}$ & $14.12 \pm 0.27^{b}$ & $16.80 \pm 1.04^{a}$ \\
\hline & & ATCC 33847 & $16.78 \pm 0.49^{b}$ & $10.00 \pm 1.39^{d}$ & $17.00 \pm 0.52^{b}$ & $13.80 \pm 1.53^{c}$ & $13.30 \pm 1.05^{c}$ & $18.20 \pm 0.89^{a}$ \\
\hline & \multirow[t]{2}{*}{ Urease } & ATCC 17802 & $21.22 \pm 1.23^{a}$ & $16.02 \pm 1.98^{c}$ & $18.46 \pm 0.58^{b}$ & $15.33 \pm 0.74^{d}$ & $16.92 \pm 0.32^{c}$ & $11.58 \pm 1.02^{\mathrm{e}}$ \\
\hline & & ATCC 33847 & $24.30 \pm 0.69^{a}$ & $15.88 \pm 1.34^{c}$ & $19.60 \pm 1.08^{b}$ & $15.10 \pm 1.19^{d}$ & $17.10 \pm 0.52^{c}$ & $10.94 \pm 1.25^{\mathrm{e}}$ \\
\hline & \multirow[t]{2}{*}{ DNase } & ATCC 17802 & $26.28 \pm 1.76^{\mathrm{a}}$ & $12.30 \pm 0.96^{d}$ & $19.76 \pm 1.03^{b}$ & $13.54 \pm 2.10^{d}$ & $16.40 \pm 0.99^{c}$ & $12.42 \pm 1.45^{d}$ \\
\hline & & ATCC 33847 & $27.90 \pm 0.81^{\mathrm{a}}$ & $13.90 \pm 0.68^{d}$ & $18.82 \pm 1.20^{b}$ & $12.42 \pm 1.16^{\mathrm{e}}$ & $17.04 \pm 0.36^{c}$ & $14.00 \pm 1.05^{d}$ \\
\hline & \multirow[t]{2}{*}{ Amylase } & ATCC 17802 & $18.34 \pm 1.11^{\mathrm{a}}$ & $16.64 \pm 1.21^{c}$ & $17.08 \pm 0.29^{b}$ & $15.40 \pm 1.08^{c}$ & $17.52 \pm 0.40^{b}$ & $15.30 \pm 1.64^{c}$ \\
\hline & & ATCC 33847 & $20.80 \pm 1.62^{a}$ & $17.12 \pm 0.53^{d}$ & $17.99 \pm 0.65^{c}$ & $13.70 \pm 1.58^{\mathrm{e}}$ & $18.98 \pm 0.25^{b}$ & $18.20 \pm 0.78^{c}$ \\
\hline
\end{tabular}

Note: ${ }^{f}$ Mean \pm standard deviation of three replicates. Means in the same line with different superscript letters are significantly different $(p<0.05)$. Results were negative for the filtrates of all food matrices not inoculated with $V$. parahaemolyticus

virulent in that it caused more deaths. There were no deaths in the control groups.

\section{Liver and kidney damage in mice}

The serum biochemical parameters indicative of liver and kidney function measured at $12 \mathrm{~h}$ in mice injected with different food matrix filtrates are shown in Fig. 2. In pork samples, no significant changes $(p>0.05)$ were detected in most of the parameters compared with the controls. AST and ALT activity indicative of liver damage were significantly higher $(p<0.05)$ in mice given shrimp, freshwater fish, chicken and egg fried rice filtrates compared with the respective controls. ALP was significantly higher $(p<0.05)$ only in mice given shrimp. BUN activity indicative of kidney damage was significantly elevated $(p<0.05)$ in all test mice injected with oyster $>$ freshwater fish $>$ shrimp $>$ chicken $>$ pork $>$ egg fried rice, compared with the respective controls. The food matrix filtrates of ATCC 33847 affected liver and kidney function more than ATCC 17802.

\section{Discussion}

A correlation between virulence and the production of extracellular products by food contaminant bacteria [34-36] including by $V$. alginolyticus [37] and $V$. vulnificus [38] but little is known about the specific extracellular products of $V$. parahaemolyticus and its pathogenicity in different food matrices. To our knowledge, this study is the first to examine the extracellular products - hemolysin and six exo-enzymatic activities in two pathogenic $V$. parahaemolyticus strains in selected seafood and non-seafood and assess relative risk.

Hemolysin is an important virulence factor responsible for the pathogenicity of $V$. parahaemolyticus because it can lyse cells, especially red blood cells, and cause systemic infections [39]. In the hemolytic activity test, the two pathogenic $V$. parahaemolyticus strains produced hemolysin not only in seafood but also in non-seafood. The significantly higher $(p<0.05)$ hemolytic activity observed in egg fried rice than in shrimp $>$ freshwater fish $>$ chicken $>$ oyster $>$ pork (Fig. 1). We hypothesized that the nutrition factors in egg fried rice can also promote $V$. parahaemolyticus to produce more hemolysin, which is in agreement with Taniguchi et al. [40] and Shinoda et al. [41] who identified a lecithin-dependent hemolysin that can also cause hemolysis. So, we believe that the high lecithin concentration in eggs may induce $V$. parahaemolyticus to produce more hemolysin in egg fried rice. This is the first evidence of $V$. parahaemolyticus producing more hemolysin in lecithin-enriched food, which means that some non-seafood may in fact be equally pathogenic than the traditionally affected seafood

Table 2 Mortality in mice injected intraperitoneally with different food matrix filtrates $(n=6)$

\begin{tabular}{|c|c|c|c|c|c|c|c|c|}
\hline \multirow{2}{*}{$\begin{array}{l}\text { Measurement } \\
\text { index }\end{array}$} & \multirow[t]{2}{*}{ Strains } & \multicolumn{7}{|c|}{ Food matrix filtrates } \\
\hline & & Shrimp & Oyster & Freshwater fish & Pork & Chicken & Egg-fried rice & Control $^{a}$ \\
\hline \multirow[t]{2}{*}{ Death rate } & ATCC17802 & $2 / 6$ & $1 / 6$ & $2 / 6$ & $0 / 6$ & $1 / 6$ & $0 / 6$ & $0 / 36$ \\
\hline & ATCC33847 & $3 / 6$ & $1 / 6$ & $2 / 6$ & $0 / 6$ & $2 / 6$ & $1 / 6$ & \\
\hline
\end{tabular}

Note: Each mouse was injected intraperitoneally with $0.2 \mathrm{~mL} / 10 \mathrm{~g}$ bw of food matrix filtrate and the death rate recorded at $48 \mathrm{~h} .{ }^{\text {a }}$ Control mice were injected with filtrates of shrimp, oyster, freshwater fish, pork, chicken and egg fried rice that were not inoculated with V. parahaemolyticus 

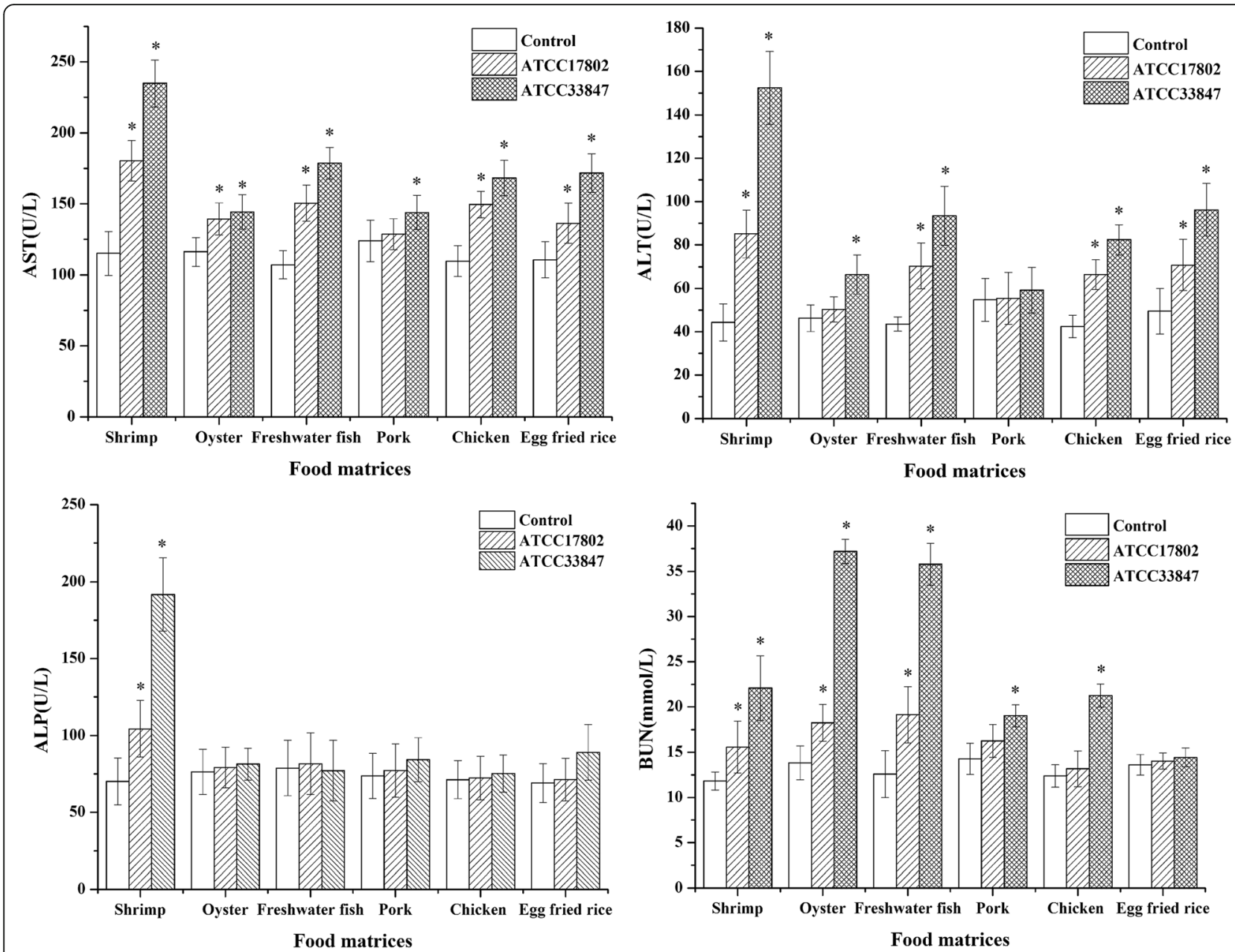

Fig. 2 Liver and kidney function indices detection. The mice were sacrificed after giving different food matrix filtrates intraperitoneally for $12 \mathrm{~h}$. The test groups given filtrates of V. parahaemolyticus ATCC 17802 (or ATCC33847) samples, control groups given filtrates of foods that were not inoculated with $V$. parahaemolyticus. Means with asterisks $\left(^{*}\right)$ are significantly different $(p<0.05)$ from the respective controls.

and therefore worthy of more attention. V. parahaemolyticus, like many other bacteria, require a source of iron and its hemolytic activity and virulence are greatly enhanced on exposure to elevated iron concentrations $[42,43]$. Hence, we believe that it is also important to pay more attention to monitoring of foods with a higher iron content. Although the mortality rates of mice injected with different food matrix filtrates (containing $V$. parahaemolyticus extracellular products) were highest in shrimp > freshwater fish $>$ chicken $>$ oyster $>$ egg fried rice $>$ pork, it was not possible to prove this statistically because of the limited number of mice used in the study.

Vibrio strains are known to produce a series of exoenzymes that contribute to expression of pathogenicity. In this study, no differences were observed in the composition of exoenzymes between the two pathogenic $V$. parahaemolyticus strains in different food matrices, which means that there is a high food safety risk no matter what food matrix type is contaminated by $V$. parahaemolyticus [44].

Results from our study suggest that $V$. parahaemolyticus produce significantly higher activity $(p<0.05)$ of gelatinase, caseinase, urease, DNase and amylaes in shrimp matrix than freshwater fish (Table 2) and are in agreement with the results of Liu et al. [31] and Zhang and Austin [32] who reported that higher phospholipase, gelatinase and caseinase activities were detected in Vibrio species isolated from marine shrimp, fish, and shark. The virulence of pathogenic Vibrios is related to their ability to produce exoenzymes [45]. As shown in Table 1, the exoenzyme activities in chicken were greater than in the oyster matrix, which suggested that V. parahaemolyticus produced more exoenzymes in the chicken and hence that some non-seafoods also pose a high risk to humans. The lower exoenzyme activities observed in pork and egg fried rice (Table 1) are interesting because Iuchi and Tanaka [46] showed that production of 
exoenzymes in $V$. parahaemolyticus was repressed by various carbohydrates present in the medium. We believe that the high concentration of carbohydrates in egg fried rice may have suppressed $V$. parahaemolyticus's ability to secrete exoenzymes. Analyzing the activities of different exoenzymes in different food matrices provides a way to comprehensively study the pathogenic mechanism of $V$. parahaemolyticus. However, further studies are required to determine which factor(s) have the most influence on the production of exoenzymes in pork and chicken.

Although cytotoxicity assays $[15,47]$ are often used to study the pathogenicity of vibrio extracellular products, in vitro tests do not adequately represent the true toxicity in vivo [48]. In our study, the mouse model was used to determine the toxicity of $V$. parahaemolyticus extracellular products. It was observed that shrimp filtrate was highly lethal to adult mice (Table 2) and caused more damage to liver and kidney (Fig. 2) than other food matrix filtrates, followed by freshwater fish and chicken filtrates. It was interesting to observe that egg fried rice, which showed the highest hemolytic activity, did not cause significant pathogenicity to mice. This is in contrast to the traditional view that hemolysin is the major virulence factors of $V$. parahaemolyticus and that the high hemolytic activity is responsible for most of the tissue damage [49]. We believe that the pathogenicity of $V$. parahaemolyticus extracellular products is dependent not only on hemolysin, but also on the mixture of other secreted enzymes. Xu et al. [13] and Bhattacharjee et al. [50] demonstrated that pathogenic $V$. parahaemolyticus, although lacking hemolysin, can still cause cytotoxicity and death in mice. Other studies have also suggested that hemolysin is not necessarily the only virulence factor of pathogenic $V$. parahaemolyticus $[39,51]$. Liver and kidney damage, as shown by elevated clinical chemistry indices such as ALT, ALP, AST and BUN activity (Fig. 2), were observed in mice given shrimp filtrate and to a lesser extent in mice given pork or egg-fried-rice filtrates. According to Maeda and Yamamoto [52], the high levels of exoenzyme activity alone could cause extensive damage to host tissue. In addition, damage to spleen and stomach were observed in mice given shrimp filtrate (unpublished observation). Our mouse results are in agreement with the findings of Moreno and Landgraf [38] and provide further proof that exoenzymes play a vital role in the pathogenicity of $V$. parahaemolyticus. Hence it is important to consider the extracellular enzymes activities also in risk assessment. Besides, the type III secretion (T3SS) system of $V$. parahaemolyticus also play a role in lethality in the murine infection model [14] although the mechanism of action of the T3SS system that influences the virulence is not well understood.
Baffone and others $[34,53]$ demonstrated that most of the extracellular products identified in $V$. alginolyticus and $V$. vulnificus are not directly associated with pathogenicity but require the bacterial cells also to be present to cause pathogenicity, unlike $V$. parahaemolyticus where the extracellular products alone can be pathogenic. In our studies also, the extracellular products of $V$. parahaemolyticus alone were pathogenic to mice. It is suggested that the pathogenesis mechanism of $V$. parahaemolyticus is different to other Vibrio types. Besides the invasion damage caused by the bacteria, the virulence factors of $V$. parahaemolyticus are highly toxic to tissues. If the food matrices are contaminated by $V$. parahaemolyticus, transient heating could remove most of the bacteria, but some thermo-tolerant products including thermostable direct hemolysin, thermostable related hemolysin, and other thermo-tolerant enzymes that can survive at $85{ }^{\circ} \mathrm{C}$ for $10 \mathrm{~min}$ [54] would possess biological activity to induce tissue damage. Hence, food should be heated to at least $85{ }^{\circ} \mathrm{C}$ for $10 \mathrm{~min}$ to destroy the activity of pathogenic thermo-tolerant products of $V$. parahaemolyticus. Besides, the food producers could incorporate probiotics (eg: Lactobacillus pentosus, Streptomyces) $[55,56]$ to inhibit the growth of $V$. parahaemolyticus and reduce the production of pathogenic extracellular products. If humans are infected with $V$. parahaemolyticus, bacteriophage therapy $[57,58]$ could be used to control and inhibit the virulence of Vibrio species. Such methods can be regarded as better strategies in view of the ever-increasing anti-microbial resistance in both humans and animals.

\section{Conclusions}

The present study suggests that the food matrix type has a marked effect on the pathogenicity of extracellular products of $V$. parahaemolyticus. Higher hemolytic activity observed in egg fried rice is an important new finding from a food safety aspect. Significantly higher activity of exoenzymes observed in shrimp and freshwater fish was strongly linked to high pathogenicity. This is the first report to show that besides the extracellular products in shrimp produced by $V$. parahaemolyticus, some non-seafood such as chicken infected with $V$. parahaemolyticus may also be toxic to mice in vivo. Although, for non-seafood matrices such as chicken it is unlikely that high levels of $V$. parahaemolyticus could be reached by cross-contamination from seafood matrices or via cooking utensils, the high pathogenicity still exists and need to be paid attention. It appears that exoenzymes, in addition to hemolysin, are involved in the pathogenesis of $V$. parahaemolyticus in food matrices. 


\section{Acknowledgements}

The authors wish to thanks Prof. Dr. Lijun Sun, College of Food Science and Technology, Guangdong Ocean University for his contribution on the design and supervised the entire study.

\section{Funding}

The design of the study, experimentation, and interpretation of the data was funded by the National Science Fund (NO. 31371746), and the higher educational program for cultivating major scientific research projects of Guangdong Ocean University (Nos GDOU 2013050205, 2014050203) and the scientific research program of administration of quality and technology supervision of guangdong province (NO. 2015ZZ02) for their financial support.

\section{Availability of data and materials}

The datasets used and/or analyzed during the current study are available from the corresponding author on reasonable request.

\section{Authors' contributions}

RW participated in the project conception, carried out all the experimental work, analyzed and interpreted the data and wrote the manuscript. LS and YW were corresponding author, designed and supervised the entire project. $Y D, Z F, Y L, Q D, D S$ and $R G$ contributed to the design and interpretation of experimental results, as well as editing and revising the manuscript. All authors have read and approved the final manuscript.

\section{Ethics approval and consent to participate}

The animal work presented in this study was approved by the Animal Care and Welfare Committee of Guangdong Ocean University (SYXK 2014-0053).

\section{Consent for publication}

Not applicable.

\section{Competing interests}

The authors declare that they have no competing interests.

\section{Publisher's Note}

Springer Nature remains neutral with regard to jurisdictional claims in published maps and institutional affiliations.

\section{Author details}

${ }^{1}$ College of Food Science and Technology, Guangdong Provincial Key Laboratory of Aquatic Product Processing and Safety, Key Laboratory of Advanced Processing of Aquatic Products of Guangdong Higher Education Institution, Guangdong Ocean University, Zhanjiang 524088, China. ${ }^{2}$ Centre for Food Research and Innovation, Department of Wine, Food and Molecular Biosciences, Lincoln University, Lincoln, Canterbury 7647, New Zealand.

Received: 3 December 2017 Accepted: 22 June 2018

\section{Published online: 05 July 2018}

\section{References}

1. Hlady WG, Klontz KC. The epidemiology of Vibrio infections in Florida 1981- 1993. J Infect Dis. 1996:173:1176-83.

2. Daniels NA, Mackinnon L, Bishop R, Altekruse S, Ray B, Hammond RM, Thompson S, Wilson S, Bean NH, Griffin PM, Slutsker L. Vibrio parahaemolyticus infections in the United States, 1973-1998. J Infect Dis. 2000;81:1661-6.

3. Su YC, Liu C. Vibrio parahaemolyticus: a concern of seafood safety. Food Microbiol. 2007:24:549-58.

4. Abd-Elghany SM, Sallam Kl. Occurrence and molecular identification of Vibrio parahaemolyticus in retail shellfish in Mansoura. Egypt Food Control. 2013:33:399-405.

5. Letchumanan V, Pusparajah P, Tan L T, Yin W F, Lee L H, Chan K G. Occurrence and antibiotic resistance of Vibrio parahaemolyticus from shellfish in Selangor, Malaysia. Front Microbiol 2105; 6:1417.

6. McLaughlin JB, DePaola A, Bopp CA, MartinekK A, Napolilli NP, Allison CG, Murray SL, Thompson EC, Bird MM, Middaugh JP. Outbreak of Vibrio parahaemolyticus gastroenteritis associated with Alaskan oysters. New Engl J Med. 2005;353:1463-70.
7. Letchumanan V, Chan K, Lee L. Vibrio parahaemolyticus: a review on the pathogenesis, prevalence and advance molecular identification techniques. Front Microbiol. 2014;5:705

8. Albuquerque $\mathrm{CR}$, Araújo RL, Souza OV, Vieira RH. Antibiotic-resistant Vibrios in farmed shrimp. Biomed Res Int. 2015:2015:505914.

9. Romilio TE, Katherine G, Nicolas P. Insight into the origin and evolution of the Vibrio parahaemolyticus pandemic strain. Front Microbiol. 2017;8:1397.

10. Shinoda S. Sixty years from the discovery of Vibrio parahaemolyticus and some recollections. Biocontrol Sci. 2011;16:129-37.

11. Xu M, Yamamoto K, Honda T, Xu M. Construction and characterization of an isogenic mutant of Vibrio parahaemolyticus having a deletion in the thermostable direct hemolysin-related hemolysin gene (trh). Publications Office of the European Union. 2010;176:4757-60.

12. Broberg CA, Calder TJ, Orth K. Vibrio parahaemolyticus cell biology and pathogenicity determinants. Microbes Infect. 2011:13:992-1001.

13. Vongxay K, Wang S, Zhang X, Wu B, Hu H, Pan Z, Chen S, Fang C. Pathogenetic characterization of Vibrio parahaemolyticus isolates from clinical and seafood sources. Int J Food Microbiol. 2008;126:71-5.

14. Hiyoshi $\mathrm{H}$, Kodama $\mathrm{T}$, lida $\mathrm{T}$, Honda $\mathrm{T}$. Contribution of Vibrio parahaemolyticus virulence factors to cytotoxicity, enterotoxicity and lethality in mice. Infect Immun. 2010;78(4):1772-80.

15. Honda $T$, lida $T$. The pathogenicity of Vibrio parahaemolyticus and the role of the thermostable direct haemolysin and related haemolysins. Rev Med Microbiol. 1993;4:106-13.

16. Kaper JB, Campen RK, Seidler RJ, Baldini MM, Falkow S. Cloning of the thermostable direct or Kanagawa phenomenon associated hemolysin of Vibrio parahaemolyticus. Infect Immun. 1984:45:290-2

17. Nishibuchi M, Hill WE, Zon G, Payne WL, Kaper JB. Synthetic oligodeoxyribonucleotide probes to detect Kanagawa phenomenonpositive Vibrio parahaemolyticus. J Clin Microbiol. 1986;23:1091-5.

18. Alam M, Miyoshi SI, Yamamoto S, Tomochika Kl, Shinoda S. Expression of virulence related properties by an intestinal adhesiveness of Vibrio mimicus strains isolated from aquatic environments. Appl Environ Microbiol. 1996;62: $3871-4$

19. Osawa R, Okitsu T, Morozumi H, Yamai S. Occurrence of urease-positive Vibrio parahaemolyticus in Kanagawa, Japan, with specific reference to presence of thermostable direct hemolysin (TDH) and the TDH-related hemolysin genes. Appl Environ Microbiol. 1996:62:725-7.

20. Harrington DJ. Bacterial collagenases and collagen-degrading enzymes and their role in human disease. Infect Immun. 1996:64:1885-91.

21. Hase CC, Finkelstein RA. Bacterial extracellular zinc-containing metalloproteases. Microbiol Rev. 1993;57:823-37.

22. Fiore AE, Michalski JM, Russel RG, Sears CL, Kaper JB. Cloning, characterization, and chromosomal mapping of a phospholipase (lecithinase) produced by Vibrio cholerae. Infect Immun. 1997;65:3112-7.

23. Rodrigues DP, Ribeiro RV, Alves RM, Hofer E. Evaluation of virulence factors in environmental isolates of Vibrio species. Mem Inst Oswaldo Cruz. 1993: 88(4):589-92.

24. Cai YL, Ni Y. Purification, characterization, and pathogenicity of urease produced by Vibrio parahaemolyticus. J ClinLab Anal. 1996;10:70-3.

25. Wu YN, Wen J, Ma Y, Ma XC, Chen Y. Epidemiology of foodborne disease outbreaks caused by Vibrio Vibrio parahaemolyticus, China, 2003-2008. Food Control. 2014:46:197-202.

26. Chao GX, Jiao XA, Zhou XH, Yang ZQ, Huang JL, Zhou LP, Qian XQ. Distribution, prevalence, molecular typing, and virulence of Vibrio parahaemolyticus isolated from different sources in coastal province Jiangsu, China. Food Control. 2009;20:907-12.

27. Tunung R, Margaret S, Jeyaletchumi P, Chai LC, Ghazali FM, Nakaguchi Y, Nishibuchi M, Son R. Prevalence and quantification of Vibrio parahaemolyticus in raw salad vegetables at retail level. J Microbiol Biotechnol. 2010;20:391-6.

28. Wang RD, Sun LJ, Wang YL, Deng YJ, Liu Y, Xu DF, Liu HM, Ye RY, Gooneratne R. Pathogenicity of Vibrio parahaemolyticus in different food matrices. J Food Protect. 2016:79:288-93.

29. Takamatsu D, Osaki M, Sekizaki T. Thermosensitive suicide vectors for gene replacement in Streptococcus suis. Plasmid. 2001:46:140-8.

30. Jiang HW, Wang KG, Zhang YQ, Huang Q, Hu XX, Yang RY. A quantitative determination of Vibrio parahaemolyticus hemolytic activity. Military Med Sci. 2013;37(4) [In Chinese]

31. Liu PC, Lee KK, Chen SN. Isolates of Vibrio harveyi from diseased kuruma prawns Penaeus japonicus. Curr Microbiol. 1996;22:413-6. 
32. Zhang $\mathrm{XH}$, Austin B. Pathogenicity of Vibrio harveyi to salmonids. J Fish Dis. 2000;23:93-102

33. Liu XF, Li Y, Li JR, Cai LY, Li XX, Chen JR, Lyu SX. Isolation and characterisation of Bacillus spp. antagonistic to Vibrio parahaemolyticus for use as probiotics in aquaculture. World J Microb Biot. 2015;31:791-805.

34. Baffone W, Citterio B, Vittoria E, Casaroli A, Pianetti A, Campana R, Bruscolini F. Determination of several potential virulence factors in Vibrio spp isolated from sea water. Food Microbiol. 2001;18:479-88.

35. Edberg SC, Gallo P, Kontnick C. Analysis of the virulence characteristics of bacteria isolated from bottled, water cooler and tap water. Microb Ecol Health Dis. 2009;9:67-77.

36. Shin-Ichi M. Extracellular proteolytic enzymes produced by human pathogenic Vibrio species. Frontiers Microbiol. 2013;4 339-339

37. Liu XF, Zhang H, Liu X, Gong Y, Chen Y, Cao Y, Hu C. Pathogenic analysis of Vibrio alginolyticus infection in a mouse model. Folia Microbiol. 2014;59: $167-71$.

38. Moreno ML, Landgraf M. Virulence factors and pathogenicity of Vibrio vulnificus strains isolated from seafood. J Appl Microbiol. 1998;84:747-51.

39. Park K, Ono T, Rokuda M, Jang M, lida T, Honda T. Cytotoxicity and enterotoxicity of the thermostable direct hemolysin-deletion mutants of Vibrio parahaemolyticus. Microbiol Immunol. 2004;48:313-8.

40. Taniguchi H, Hirano H, Kubomura S, Higashi K, Mizuguchi Y. Comparison of the nucleotide sequences of the genes for the thermostable direct hemolysin and the thermolabile hemolysin from Vibrio parahaemolyticus. Microb Pathogenesi. 1986;1:425-32.

41. Shinoda S, Matsuoka H, Tsuchie T, Miyoshi S, Yamamoto S, Taniguchi H, Mizuquchi Y. Purification and characterization of a lecithin-dependent haemolysin from Escherichia coli transformed by a Vibrio parahaemolyticus gene. J Gen Microbiol. 1991;137:2705-11.

42. Kustusch RJ, Kuehl CJ, Crosa JH. Power plays: iron transport and energy transduction in pathogenic vibrios. Biol Met. 2011;24:559-66.

43. Wright AC, Simpson LM, Oliver JD. Role of iron in the pathogenesis of Vibrio vulnificus infections. Infect Immun. 1981;34:503-7.

44. Chen J, Zhang RH, Qi XJ, Zhou B, Wang JK, Chen Y, Zhang HX. Epidemiology of foodborne disease outbreaks caused by Vibrio parahaemolyticus during 2010-2014 in Zhejiang Province, China. Food Control. 2017;77:110-15.

45. Nottage AS, Birkbeck TH. Purification of a proteinase produced by the bivalve pathogen Vibrio alginolyticus NCMB 1339. J Fish Dise. 1987;10: $211-20$.

46. Iuchi S, Tanaka S. Catabolite-like repression of extracellular enzyme production in Vibrio parahaemolyticus. Microbiol Immunol. 1980;24:803-14.

47. Oliver JD, Wear JE, Thomas MB, Warner M, Linder K. Production of extracellular enzymes and cytotoxicity by Vibrio vulnificus. Diagn Microbiol Infect Disenso. 1986;5:99-111.

48. Yeung PS, Wiedmann M, Boor KJ. Evaluation of a tissue culture-based approach for differentiating between virulent and avirulent Vibrio parahaemolyticus strains based on cytotoxicity. J Food Protect. 2007;70: 348-54.

49. Nair GB, Ramamurthy T, Bhattacharya SK, Dutta B, Takeda Y, Sack DA. Global dissemination of Vibrio parahaemolyticus serotype o3:k6 and its serovariants. Clin Microbiol Rev. 2007;20:39-48.

50. Bhattacharjee RN, Park KS, Okada K, Kumagai Y, Uematsu S, Takeuchi O, Akira S, lida T, Honda T. Microarray analysis identifies apoptosis regulatory gene expression in HCT 116 cells infected with thermostable direct hemolysin-deletion mutant of Vibrio parahaemolyticus. Biochem. Bioph Res Co. 2005:335:328-34

51. Lynch T, Livingstone S, Buenaventura E, Lutter E, Fedwick J, Buret AG, Graham D, Devinney R. Vibrio parahaemolyticus disruption of epithelial cell tight junctions occurs independently of toxin production. Infect Immun. 2005:73:1275-83.

52. Maeda $\mathrm{H}$, Yamamoto T. Pathogenic mechanisms induced by microbial proteases in microbial infections. Biol Chem Hoppe Seyler. 1996:377:217-26.

53. Baffone W, Pianetti A, Bruscolini F, Barbieri E, Citterio B. Occurrence and expression of virulence-related properties of Vibrio species isolated from widely consumed seafood products. Int J Food Microbiol. 2000;54:9-18.

54. Sakurai J, Matsuzaki A, Miwatani T. Purification and characterization of thermostable direct hemolysin of Vibrio parahaemolyticus. Infect Immun. 1973;8:775-80
55. Sha YJ, Wang BJ, Liu M, Jiang KY, Wang L. Interaction between Lactobacillus pentosus HC-2 and Vibrio parahaemolyticus E1 in Litopenaeus vannamei in vivo and in vitro. Aquaculture. 2016;465:117-23.

56. Tan LTH, Lee LH, Goh BH, Chan KG, Wright V. Streptomyces bacteria as potential probiotics in aquaculture. Front Microbiol. 2016;1:1-8.

57. Letchumanan V, Chan KG, Pusparajah P, Saokaew S, Duangjai A, Goh BH, Ab Mutalib NS, Lee LH. Insights into bacteriophage application in controlling Vibrio species. Front Microbiol. 2016;7:1114.

58. Jassim SAA, Limoges RG. Natural solution to antibiotic resistance: bacteriophages "the living drugs". World J Microbiol Biotechnol. 2014;30: 2153-70.

\section{Ready to submit your research? Choose BMC and benefit from:}

- fast, convenient online submission

- thorough peer review by experienced researchers in your field

- rapid publication on acceptance

- support for research data, including large and complex data types

- gold Open Access which fosters wider collaboration and increased citations

- maximum visibility for your research: over $100 \mathrm{M}$ website views per year

At BMC, research is always in progress.

Learn more biomedcentral.com/submissions 